Book Review

\title{
I Met Lucky People: The Story of the Romani Gypsies. By Yaron Matras. London: Allen Lane, Penguin Books, 2014, 276 pp.; ISBN 978-1-846-
}

\section{1-3.}

\author{
Victor A. Friedman \\ Department of Linguistics, University of Chicago, Chicago, IL 60637, USA; E-Mail: vfriedm@uchicago.edu
}

Submitted: 26 April 2015 | Accepted: 4 May 2015 | Published: 29 September 2015

\begin{abstract}
This is a book review of I met lucky people: The story of the Romani Gypsies, by Yaron Matras. The work is oriented for a general reading public, but it can be highly recommended for academics and policy makers as well.
\end{abstract}

\section{Keywords}

Gypsies; history; language; Romani; society

\section{Issue}

This book review is part of the special issue "Talking about Roma: Implications for Social Inclusion", edited by Dr. Eben Friedman (Independent Consultant and Senior Non-resident Research Associate, European Centre for Minority Issues, Germany).

(C) 2015 by the author; licensee Cogitatio (Lisbon, Portugal). This article is licensed under a Creative Commons Attribution 4.0 International License (CC BY).

While there is no dearth of books about the Romani people aimed at the general reading public and published by commercial publishers with broad networks of distribution, few of them can be recommended, and there are almost no such general works by specialists in Romani Studies. There is, perhaps, a twofold explanation for this situation. First, as a fully fledged academic discipline, Romani Studies as such is relatively young. Although the serious study of the Romani language is arguably as old as the field of modern linguistics itself, and anthropological ethnographies of Romani communities also have a long and significant tradition, the current burgeoning of academic interest in Romani subjects dates more or less from the so-called fall of Communism and the rise of the European Union. As symptomatic of this state of affairs is the fact that the North American Chapter of the Gypsy Lore Society was founded in 1979 in part as a reaction to the marginalization felt by anthropologists working with Romani communities. At that time, the overwhelming majority of scholars working in Romani Studies were anthropologists, linguists, and ethnographers of music and dance. It is only in the past couple of decades or so that we have seen the rise of a large community of scholars in a great diversity of humanistic and social scientific disciplines for whom Romani Studies is the center, or one of the centers, of their academic focus. The second part of the explanation is arguably the fact that popular books do not count in the building of an academic profile. Rare or non-existent is the academic who will get tenure or promotion on the basis of such a book. The Academy has thus provided a double disincentive to scholars wishing to write about the Romani people for a general audience. Until recently, Romani Studies were as marginalized as the Romani people, and even now that Romani Studies is more broadly accepted as a serious discipline, the popularization of academic knowledge is not encouraged by the system. We are fortunate, therefore, that a scholar with almost three decades of both practical and academic experience in Romani Studies and one of the leading specialists in the field has decided to write such a book. Moreover, the book does exactly what it is supposed to do in terms of popular, general ethnography and history. It thus fills an important gap in the literature on the Romani people.

The book is divided into eight chapters, an appendix, two maps, a bibliography, and an index. In the first chapter, Who are the Romani People (pp. 1-30), Matras 
defines the topic and goal of his book: "to provide an overview of Romani communities, their customs, their social organization and their history" (p. 27). As he immediately notes, a truly comprehensive survey of the many Romani-speaking groups-let alone groups of Romani descent who no longer speak the languagewould require an encyclopedia, and he must, therefore, limit himself to a selection. But his selection is as broad and representative as can be achieved for any relatively large ethnic, ethno-national, or national group in a popular monograph of this nature. (My use of national here does not mean requiring a nation state but refers only to the social identity category implied by the term nationality, to which Romani is recognized as belonging by a variety of governments.) Matras dismisses the pernicious constructivist perversion that Roms do not exist outside the imagination of majority populations with the following words: "But try entering the home of a Romani family and saying to their faces: 'You are not really Roms, you are just a construction of our imagination, a product of our romantic fantasies, there are no real Gypsies'..." (p. 28). In this chapter Matras also presents a good basic overview of the Indic origins of the Romani people and their language, and discussions of the terms Gypsy and Tsigan, and their cognates. He adduces here the most recent scholarly arguments that the European term Tsigan-, etc., is from Turkish Çingene, which then entered Greek, where the sound represented by Turkish $c$ (the $c h$ of church) regularly becomes $t s$ in all borrowings. From Greek it then went throughout much of Europe. Matras concludes this chapter by making clear that his intent in providing this overview is informed by "the view that we need to rethink and revise our picture of the Romani people and to move away from the literary images and brands, and on to understanding the real everyday lives and aspirations of a real people".

Chapter Two, Romani Society (pp. 31-66), is a perceptive discussion of various aspects of Romani social organization, including mobility, work, kinship, conflict management, child rearing, education, household structure, and family values. Matras makes a variety of important points here in a compact space. As he observes: "Perhaps the key challenge facing Roms throughout the centuries, apart from mere survival in the face of persecution and exclusion, is how to maintain their own culture and identity in the absence of a territory and formal institutions" (p. 32). On this same page Matras makes the important point that "the great majority of Roms do not travel and their families have lived in permanent settlements and dwellings for many centuries." He points out that after the initial dispersal of Romani communities from the Balkans throughout Europe during the late medieval and early modern periods-i.e., the final century or two of the Byzantine and first century or two of the Ottoman Empiresmost Romani migrations have been connected with larger European migrations in general, e.g. the compulsory exchange of populations between Greece and Turkey under the 1923 Treaty of Lausanne, the migrations of East Europeans to North and South America in the late nineteenth and early twentieth centuries, the labor migration from Yugoslavia to Western Europe of the 1960s and 70s, or the exodus of refugees fleeing the wars of the 1990s in former Yugoslavia.

Matras also discusses here the distinction between those Roms who do follow a peripatetic lifestyle and other peripatetic groups, such as Travelers, the crucial distinctions being those of language and the practice of certain cultural norms. Matras' discussion of kinship (pp. 37-40) focuses on speakers of the Northern Vlax Romani dialects, which is appropriate given both the broad European and global dispersal of these Roms and the specificity of their kinship structures. Here, however, certain distinctions are elided, and while this is entirely understandable in a book of this nature and in no way dimities its value, nonetheless it requires comment in a review. In this instance, it is Matras' description of the North Vlax Romani groups as simply Vlax. This erases the distinction of the South Vlax speaking groups, who are linguistically and historically related to the North Vlax groups but culturally quite distinct. It is the South Vlax groups that migrated to what was still the Ottoman Empire during the main exodus of Vlax groups from the Romanian principalities in the nineteenth century. They thus represent the Vlax speaking groups in the southern Balkans. In this respect, as in others, the Balkans represent Romani specificities not necessarily shared with the rest of Europe. This is in part precisely because the Balkans, and especially the southern Balkans (roughly speaking the territory including and south of Bosnia-Herzegovina, southern Serbia, and Bulgaria) was the location where the Romani people first settled, and from which all subsequent Romani migrations first started out. This fact is also relevant to the section on Romani household structure. The living arrangements that Matras describes as "strongly resembl[ing]...western Asian cultures" (p. 41), are identical to those typical of the Ottoman Balkans. Such patterns of household arrangement have persisted right up to the present day, especially in some rural and conservative Muslim households, in various Balkan countries. Here, as in some other matters, what appears as typical of the Romani people in western Europe is in fact typical of the Balkans, or at least was typical of the Balkans until relatively recently.

All in all, the second chapter does an excellent job of explaining how the centrality of the extended family to the maintenance of Romani culture and identity works. Comparisons with other traditional societies are often made where appropriate, and in general the reader will get a sensitive understanding of the values and constraints of Romani family life. Chapter Three, Romani Customs and Traditions (pp. 67-100), discusses 
belief systems that include the everyday and various rites of passage, the subsections are concerned with dress and appearance, the central cultural concepts of good fortune (baxt) and shame (ladž), and cleanliness (purity), marriage, death, festivals and celebrations, music, leadership, and religion. Matras discusses the value placed on displays of wealth as honorable, e.g. in women's wearing gold, to which we can add that in Macedonia it was precisely earrings with gold coins that would be worn by every Romani girl or woman. The discussion of clothing (pp. 68-69) focuses on Christian Roms. While the stricture to wear skirts is indeed strong among Christian Romani women, Muslim Romani women wore pantaloons called shalvari (chintiyane), which, depending on the purpose (work versus celebration) would have a narrower or larger cut. As late as the early 1970s, this style of dress was uniformly practiced as far north as Belgrade, although it was eliminated in Bulgaria after World War Two by the Communist authorities. The pantaloons were covered with a very specific style of red apron with black, yellow, and/or white vertical stripes, and women covered their hair with a kerchief that was tied in a specific manner, different from that of women in other Muslim ethnic groups, all of whom covered their hair. These clothing strictures broke down in the course of the 1970 s and 1980s as a result of urban modernization, and today they are considered old-fashioned. For weddings, however, it is still traditional for women in the main bridal party to wear enormous shalvari made from nine meters of material, although more modern feminine-style trousers are gaining in popularity owing to their relative simplicity. Matras' observations about the effects of modernization are spot on. The discussion of baxt, ladž, and purity are very well done. We can note in passing that even among Roms who do not practice the kinds of ritual cleanliness codes found in the groups that Matras describes, there is a stereotype that non-Roms are "dirty". We should also note that the expressions cited by Matras as "I will eat your penis/vagina!" (p. 71) (in the dialects I am familiar with, the present tense is used) are used as expressions of intimate affection, and in fact they have no sexual connotation when used, for example, by a parent to a baby. Rather, these expressions are de facto similar to expressions such as "you're so sweet I could just eat you all up". While their translations sound quite shocking to non-Roms, in fact for Romani speakers they are simply idiomatic expressions whose literal meaning they do not even think about.

The discussion of belief in mule "ghosts, spirits of the dead" is anecdotal but effective. Here, too, the Romani belief system emerges as one quite similar to traditional belief systems in Europe. My grandmother made my mother wear an amulet to protect her from the evil eye, but firmly believed that the vampires that had threatened her in Romania could not cross the ocean to America. The discussion of marriage covers all of the basic points for various groups including those in the Balkans. The translation of bori as "daughter-inlaw" (78 and passim) is accurate, but could have been more nuanced. In fact, the primary meaning of the word is "bride", and in Romani, as in all the Balkan languages, when a bride enters a family she is the daughter-in-law of her parents-in-law, but more importantly, she is the newcomer who must be integrated into her new household. Overall, this chapter does an excellent job of discussing all the basic points that are relevant for understanding various Romani groups. In the section on music (pp. 87-91) I have a couple of small quibbles that do not detract from the overall value of the section. Matras points out that in various countries Roms often specialize in various instruments (p. 88), and while the zurna, a reed instrument related to the oboe, could be described as a 'flute' in the sense of "aerophone", in fact Roms do not specialize in bagpipes in the Balkans. This instrument is traditionally played by non-Romani peasants. We can also add that in many Balkan and west Asian communities, the instruments in which Roms do specialize (such as the zurna and the bass drum), are considered essential for a proper wedding, and thus the hiring of wedding musicians is synonymous with the hiring of Romani musicians. One other small note with regard to Romani music in Bulgaria: while çalgı is the Turkish name for a type of traditional urban ensemble music typical of the late Ottoman Balkans and surviving into the postOttoman period, in Balkan Slavic this music is called chalgiya, while chalga is the post-1989 Bulgarian pop development with analogues in all the other Balkan countries as well.

The discussion of leadership is well presented, although I would have used the literal translation of Baro Rom "Big Man", both because Šero "Head [Man]" sometimes also occurs and because the concept has similarities to other cultures where the concept also translates as "big man". The section on religion is also very good in its coverage. There is one statement that deserves comment, however. Matras writes: "In the Balkans switching between Islam and (mainly Orthodox) Christianity accompanied either migration from one region to another or the changing power relations in the region, with the Roms keen to align themselves with the dominant group." This statement really does require nuancing and is simply too strong. In the postOttoman Balkans, especially in Macedonia and Bulgaria, but also, to some extent, in Greece, Roms that were Muslim have remained Muslim, a fact that Matras does discus in the context of Bulgaria in Chapter Seven. In the case of Greece, this meant that Roms outside of Western Thrace were subject to the same compulsory exchange of populations as other Muslims (except the Çam Albanians). In Western Thrace, Muslims are an officially recognized minority (note that recognition is 
based on religion and not language), and Muslim Roms have retained their religion rather than identifying with the Greek Orthodox majority. Of greater significance, however, are the Muslim Romani communities in the Republic of Macedonia and in Bulgaria, which have constituted the majority of Roms in these countries and remained Muslim throughout the post-Ottoman period (except for in-roads made recently by Evangelical Christianity). These communities have chosen to maintain their religious identification with significant minority populations, rather than converting to what became the religion of the dominant state majority. In some cases, this choice can be connected with the fact that a national minority is a local majority. Thus in certain regions, or even neighborhoods, in Macedonia and Bulgaria (as well as Greek Thrace), Turks, Albanians, or Slavic-speaking Muslims constitute the local majority, and Roms have maintained their religious alignment with them. A similar explanation is arguably the case in Kosovo, which was administratively a part of Orthodoxmajority Serbia for most of the 20th century, but which had a local Muslim majority. In other cases, at times when government policies favored a positive treatment of minorities, Muslim Roms could be in a better position by identifying with other minority populations rather than the majority. One final argument in favor or Romani particularism with respect to Islam in the southern Balkans is the fact that pre-nationalist Balkan folk Islam favored the kinds of values that were consistent with Romani culture in general.

Chapter Four, Romanes: The Romani Language (pp. 101-127), is a tour de force of popular linguistics, clarifying all the important issues for the general reader. The scholar could quibble here and there, but those of us who might use this book for teaching purposesand indeed the book is on a high enough level to be suitable for that-can always supplement where needed. Given what we can deduce about Romani migrations from the Balkans, what Matras quite eloquently describes as "an almost erratic dispersion of Romani groups from and within the Balkan regions" (p. 112) occurred not so much from "the crumbling Byzantine Empire" (p. 112) as from the post-Byzantine landscape of the Bulgarian and Serbian Empires, as they were reduced to vassalage and then incorporated into the Ottoman Empire. To be sure, from a linguistic point of view, the Greek (Byzantine or Romaic) component in Romani attests to that language's early and pervasive influence. Matras also does a superb job of bringing in those languages that preceded or accompanied Byzantine Greek influence. But the early Slavic component in Romani, which Matras refers to citing Miklosich's classic work, is likewise shared across the broadest spectrum of the population. Unlike the Greek and other pre-Exodus components, however, where there are no cognate languages in Europe to confuse matters, it is the European nature of Slavic that makes identifying that layer more complex. All those Romani groups that left the Balkans moved through Slavic speaking territory, and some settled in Slavic speaking majority territories, while those that remained in the Balkans were continually in contact with Slavic in most regions. As a result, isolating a specifically early Slavic component in Romani is often extraordinarily difficult. Still, such moments are possible. Aside from the items Matras cites from Miklosich, we can note the Calò (Spanish paraRomani) zamba "frog" as an excellent example of an early Slavic loanword that was retained in a Romani group that has long been far from Slavic influence. It is also evidence that the Gitanos of Spain arrived via Europe and not North Africa. We can also note in passing that čelo should be celo $(=t s e l o)$ in the meaning "whole" (p. 113). The "once upon a time" opening that Matras cites (p. 119) as being found all over West Asia is also found in all the Balkan languages except Greek (or at least that standard variant thereof).

The discussion of the retention of retroflex (or at least distinctive) /r/ (p. 112), likewise makes the basic point of retention of aspects of Indo-Aryan phonology for a popular audience, although the educator would be better served by the example of distinctive aspiration of voiceless stops. Not only is the distinction more consistently preserved among Romani dialects, but by having Anglophone students hold their palms in front of their mouths and then pronouncing pot and spot, a point about the nature of aspiration can be made at the same time as teaching the nature of distinctive versus non-distinctive features. (Romani perel "fall" versus pherel "fill" serves as a useful example.) I must admit to being puzzled by Matras' formulation: "Romani at the time must have resembled Greek and other languages spoken in the Balkans in its sentence melody..." (p. 112). The rest of the sentence is fine, but it is precisely in matters of intonation that the various Balkan languages differ from one another, and, moreover, that Romani is also distinctive. Instrumental studies of Romani intonation-as well as those of other Balkan languages-remain an important desideratum, but my own personal experience has been that Romani intonation is distinctive. I once had the experience on the north side of Chicago of overhearing two women conversing and recognizing the intonation as being like the Romani I knew from the Balkans before I could actually make out what they were saying. As it turned out, they were speaking a Kalderash dialect from northeastern Europe. I can also note here that in the Balkans, while all Roms are thoroughly fluent in the necessary contact (majority) languages, many Romani speakers also have an ethnolectal "accent" that identifies them as Romani just as surely as African-American intonational patterns identify many or most African-Americans in the United States. At issue are physically measurable phonological frequencies, for which, in the African-American context, Alicia Wassink of the University of Washington 
(Seattle) is conducting ground-breaking basic research. It is, of course, far beyond the requirement of the book currently under review, but for readers of this journal the point is worth making.

In the discussion of Romani names for various nonRomani ethnic groups (p. 121), it is worth noting that while das can be glossed "Orthodox Christians", in general it refers specifically to Slavic speaking Orthodox Christians (balame being used for Greeks, as Matras observes). The Indic meaning of das is "slave" and the term thus appears to be an old calque on the Greco-Latinate confusion of Slavenoi with sklavenoi. It is also interesting to note that both bibolde "unbaptized" and činde "cut" (= circumcised) for Jews are specifically Christian-defined terms, since both would apply equally to Muslims.

Chapter Five, The Roms Among the Nations (pp. 118-155) is an excellent account of what we can deduce about the early history of the Roms as well as what we know about their later history from documentation. As Matras makes clear, we know for certain that the Roms left India, and that they spent enough time in contact with medieval Greek that they must have been living in the Byzantine Empire. We do not know, however, the exact date of the exodus from India nor whether it was connected with some specific event in political history. There are various possible candidates for such an event. The "Egyptians" referred to in an order of the Patriarch of Constantinople, Gregorios II Kyrpios, dated between 1283 and 1289 and levying a tax on "Athinganoi and Egyptans" in all likelihood refers the Roms (p. 130). By the fourteenth century, we begin to have numerous references that clearly involve Roms, and from then on there are increasingly numerous documentary sources. This chapter does a masterful job of covering approximately 600 years of recorded history concerning the Romani people. There was only one typographical error: Królikoa (in Poland) should be Królików (pp. 137, 161). As Matras makes clear, owing to the fact that the Roms do not possess documentation of their own early history, what we know is based on the records of those with whom they came in contact. Matras closes this chapter with the period when there was a general shift in attitudes towards Roms. As he writes (p. 155), by the end of the eighteenth century: “...Roms were being offered protection in the name of humanism and equal opportunities but on the condition that they abandon their traditions and separate identity."

Chapter Six, Baptized Heathens: Between Romanticism and Racism (pp. 156-183), basically picks up the historical thread in the eighteenth century, by which time Roms have become a significant factor in European artistic production. As Matras acknowledges, Gypsies were already the subjects of artistic production in the renaissance and baroque periods. Here we can note that the Italian renaissance poet Angelo Ambrogi- ni ("Poliziano"), who lived 1454-1494, produced his Canzone zingaresca "Gypsy song" well before the 1521 poem in Old Spanish cited by Matras (p. 161). The words of Jacob Burkhardt (1878, p. 102) are worth citing here: “His [Poliziano's] gipsy's [sic] love-song is one of the earliest products of that wholly modern tendency to put oneself with poetic consciousness into the position of another class. This had probably been attempted for ages with a view to satire, and the opportunity for it was offered in Florence at every carnival by the songs of the maskers. But the sympathetic understanding of the feeling of another class was new; and with it the 'Nencia' and this 'Canzone zingaresca' mark a new starting-point in the history of poetry." We can also note in passing that Mikša Pelegrinović's poem Jeđupka "The Gypsy Woman", produced between 1525 and 1527 and modeled on the Italian zingaresca genre, is one of the most popular classics of Croatian renaissance literature. The Gypsy, like the Jew, was one of the stereotypical "others" mocked in Italian carnival traditions, but from this mockery grew the earliest literary representations as well. As Matras rightly observes, the Romantic period in the nineteenth century sees an enormous growth in artistic representations of Roms, which representations have continued into the twentieth and twenty-first centuries. He also makes the important point that "[u]nderstanding the literary images of Gypsies that the arts cultivated, and continue to cultivate, is therefore an essential key to understanding Romani history and the history of society's attitudes towards the Roms." (p. 157). This approach enables Matras to move from a well chosen coverage of nineteenth and post-nineteenth century artistic works to the nineteenth and post-nineteenth century world of the European nation state in which those artistic works were produced. In this second part of the chapter, Matras covers the grim history of the Romani people that led to the Romani genocide of World War Two, for which Matras gives meticulously researched details. Moreover, as Matras observes: "None of those involved in the genocide of Roms under the Nazis were brought to justice after the war" (p. 183). Matras then names some of those who were responsible but who never faced criminal charges.

Chapter Seven, Romani Identity in the Twenty-first Century (pp. 184-224) picks up the story after World War Two. Here Matras makes the point that "[w]hile Jewish victims [of the Holocaust] were granted prima facie recognition as victims of racial persecution, Roms were denied such recognition." (p. 185). In this chapter Matras documents the Romani struggle for the recognition that their suffering, like that of the Jews, was motivated by Nazi racist ideology, a recognition that was, after decades, finally achieved. Matras also discusses the discriminatory and assimilatory policies pursued by various post-War East European Communist regimes. In detailing the discriminatory policies of the 
Bulgarian state against Muslim Roms and Turks (pp. 190-191), we should add that Bulgarian-speaking Muslims, known as Pomaks, were likewise subjected to various forms of cultural oppression such as forced name changes. The Bulgarian state's battle against what historian Mary Neuburger has called The Orient within (2004) was a battle against Islam, and as such included the majority of Bulgaria's Roms. This section also documents more positive events, such as the recognition of Roms in the republics of former Yugoslavia. The discussion then moves to the post-1989 era, which sees the rise of Romani political involvement as well as Romani participation in population movements made possible by newly opened borders. It is perhaps worth noting that in addition to the parties cited by Matras, the Party for the Complete Emancipation of the Roms in the Republic of Macedonia was among the first Romani identified political parties to enter into ruling coalitions. This is especially noteworthy since the Republic of Macedonia was the only Yugoslav republic in which ethnic political parties did not overwhelm nonethnic parties in the 1990 elections. This chapter does an excellent job of bringing the story of Romani politics up to the present day. Here Matras speaks with the authority of both the meticulous researcher and the practitioner, since he himself has been an active participant in the struggle for a fair and just treatment of the Romani people.

The eighth and final chapter, Conclusion (pp. 225229 ) is a brief meditation on the challenges of writing about a marginalized people and on the changes being wrought by a new era of globalization. This is followed by Appendix: The Mosaic of Romani Groups (pp. 231240), which includes a map. The appendix is followed by two maps giving Additional References on Romani Language (pp. 241-242) illustrating some of the major dialectal divisions within Romani using a well chosen selection of diagnostic words. These are all very effective in conveying technical information to a nonspecialist audience. The Select Bibliography (pp. 245250 ) is divided by subject matter-History, Culture and Society, Images of Gypsies, Language, Politics-and contains about a hundred items, all of them appropriate. The book concludes with an Index (pp. 251-276).

As a popularly oriented account of the Romani people, Matras' book is unmatched in both the quality and the quantity of information that it successfully conveys. Moreover, it is written in a lucid and engaging style that makes it a very pleasurable read. It can be recommended without any reservations whatsoever to both popular and academic audiences, as well as to policy-oriented audences. Matras has done the general reading public, the academic and policy communities, and, perhaps most important, the Romani people a tremendous service in producing this book. It is a deeply sympathetic account that at the same time succeeds in beng academically sound. It deserves to be purchased by both public and academic libraries. It should be required reading for policy-makers as well as any academic whose work deals in any way with the Romani people, and we can hope that it will reach the broad audience for which it is intended.

\section{Conflict of Interests}

The author declares no conflict of interests.

\section{References}

Burkhardt, J. (1878). The civilisation of the period of the Renaissance in Italy (TransI. S.C.G). Middlemore London.

\section{About the Author}

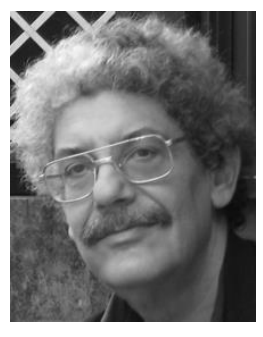

\section{Dr. Victor A. Friedman}

Victor A. Friedman (Ph.D., University of Chicago, 1975) is Andrew W. Mellon Distinguished Service Professor Emeritus in the Department of Linguistics at the University of Chicago. He was also Director of Chicago's Center for East European and Russian/Eurasian Studies (2005-2015). He has held Guggenheim, Fulbright-Hays, ACLS, IREX, NEH, and other fellowships. His publications include books on Macedonian, Albanian, and Turkish as well as more than 200 scholarly articles. His main research interests are grammatical categories and sociolinguistic issues related to contact, standardization, ideology, and identity in the languages of the Balkans and the Caucasus. 